\title{
Dossier: Rostros de la biografía latinoamericana ${ }^{1}$
}

La biografía es un género de muy antigua data. Si bien se tienen referencias sobre su aparición entre autores persas de lengua griega como Scylax y Xantos, cuyas obras, desaparecidas, se remontan al siglo V. a. de C., es a partir de la modernidad que se le considera parte del discurso historiográfico propiamente tal, o que se aprecia su calidad literaria. Arnaldo Momigliano sostiene que sus cultores clásicos no lo tuvieron como parte de la escritura histórica y recién la biografía inglesa de los siglos XVII y XVIII (autores como Samuel Johnson, James Boswell y John Aubrey) le confirió un carácter particularmente literario.

Surgida sobre todo como un género con afanes moralizadores y didácticos, durante siglos los sujetos biografiables fueron varones que ocupaban posiciones de poder. Las derivas contemporáneas de la biografía nos llevan, por el contrario, hacia caminos muy diversos, en que un anónimo sujeto puede llegar a ser con toda justicia biografiable, un giro experimentado a partir del siglo XIX y que se ha consolidado junto con una serie de conceptos provenientes de la historia social y sus más recientes desarrollos.

En este dossier nos propusimos abordar diversos problemas relativos a la escritura biográfica en el contexto latinoamericano durante los siglos XIX y XX. Actualmente se cuenta con una gran cantidad de estudios sobre la biografía histórica en Europa y Estados Unidos (François Dosse, Carlo Ginzburg, Giovanni Levi, Simon Schama), así como también un material ensayístico considerable sobre la biografía literaria, muchos de ellos textos escritos por sus propios cultores en lengua inglesa o francesa. Pero parecía ser que en el espacio latinoamericano se trataba aún de un corpus nuevo de investigación, con interesantes perspectivas y muchos rostros, que es posible abordar desde el cruce de diversas disciplinas, temporalidades y registros. Fue sobre todo esta cualidad

1 La realización de este dossier y del siguiente texto se debe a los proyectos proyecto Fondecyt Iniciación No 11140881, del cual es responsable la Dra. Claudia Darrigrandi, y Fondecyt Regular No 1150061, dirigido por la Dra. Lorena Amaro. 
la que se quiso destacar con la publicación de este dossier, donde se ofrece una selección de artículos provenientes, en su mayoría, de las Jornadas "Vidas ajenas: perfiles, retratos y biografías latinoamericanos", llevadas a cabo entre el 24 y el 25 de mayo de 2016, coorganizadas por el Instituto de Estética de la Pontificia Universidad Católica de Chile y el Centro de Investigación y Documentación (CIDOC) de la Facultad de Comunicaciones y Humanidades de la Universidad Finis Terrae. El objetivo de esta actividad fue generar un espacio para discutir sobre la escrituras de vidas que no solo se ajustasen a lo que se ha entendido hasta ahora como escritura biográfica, sea desde la literatura o la historia, en un esfuerzo que se suma a otras iniciativas continentales, como la creación de la Red de Estudios Biográficos de América Latina, encabezada por la Dra. Paula Bruno desde Argentina, una de las principales invitadas al encuentro.

De este modo, se hizo un llamado a que presentaran sus investigaciones aquellos investigadores e investigadoras que han abordado estos temas desde el estudio de la biografía histórica o literaria, pero también se consideraron propuestas de trabajos que revisaran textos genéricamente plurales como los de carácter periodístico (perfiles, retratos y entrevistas), de manera de ir asentando un corpus bibliográfico latinoamericano. En ese contexto, este dossier da cuenta de diversos problemas que surgen cuando se estudia la escritura biográfica, ya sea la relación entre biógrafo y biografiado, la escritura del yo (cuando a la vez se escribe sobre otro), las relaciones o cruces entre literatura e historia, y las dificultades de construir un sujeto biográfico, sea éste un sujeto modélico o ejemplar, o alternativo o contrahegemónico.

Este dossier comienza con el artículo "Biografía e historia de los intelectuales. Balance y reflexiones sobre la vida cultural argentina entre 1860 y 1910" de la Dra. Paula Bruno (Conicet, Argentina), quien revisita la investigación realizada en su libro Pioneros culturales de la Argentina. Biografías de una época, 1860-1910 (2011), en la que sostiene que las biografías de un grupo de intelectuales fueron la forma de abordar una época, "una trama cultural compartida" que, a su vez, a ella le posibilitó cuestionar ciertas periodizaciones de la historia argentina. Le sigue el artículo "Biografía, estatuaria y usos de género en Historia de Sarmiento de Leopoldo Lugones" de Patricio Fontana (Universidad de Buenos Aires / Conicet), en el cual se analiza la biografía de Juan Domingo Faustino Sarmiento publicada por Leopoldo Lugones en 1911. Este trabajo se de- 
tiene en la relación entre biografía y monumento, en la escritura de la genialidad del biografiado y, también, en las varias vidas de Sarmiento como un "hombre múltiple". La aproximación de Fontana sobre la relación entre biógrafo y biografiado no se sustenta en las semejanzas o diferencias entre estos, sino en que el biógrafo se formó en el programa educativo del biografiado.

En el artículo de Antonia Viu (Universidad Adolfo Ibáñez, Chile), se encuentra una operación similar a la emprendida por Bruno, pero desde la literatura, puesto que la autora se interroga por la escritura de perfiles biográficos como medio para analizar "los sentidos de lo colectivo" en las revistas Claridad y Babel. Arguye Viu que los perfiles y carteles permiten construir una colectividad, arraigada en la sociabilidad anarquista, sin que las subjetividades pierdan su autonomía y singularidad.

En el artículo "De la calle a vidas extraordinarias: entrevistas y perfiles de José Antonio Lizarazo", Claudia Darrigrandi (Universidad Finis Terrae, Chile) reflexiona sobre la escritura biográfica a partir del trabajo periodístico del escritor colombiano en Mundo al Día (1924-1927) y El Tiempo (1939-1940). Darrigrandi plantea que si en el primer medio se publicaron entrevistas de personajes de fuertes características marginales, en El Tiempo, en cambio, la escritura de los perfiles de esos mismos sujetos adquirieron cualidades ejemplificadoras como un medio para articular una crítica al partido liberal.

Horacio Molano (Universidad Nacional Autónoma de México) en el artículo "El trazo de los otros: Jaime Torres Bodet y Elías Nandino frente a Contemporáneos" analiza las experiencias literarias ilustradas por Jaime Torres Bodet en Tiempo de arena (1955) y Elías Nandino en Juntando mis pasos (2000), ambas obras autobiográficas en cuyas páginas sus autores hacen esbozos biográficos de los otros miembros de los “Contemporáneos", nombre que tomaron estos autores mexicanos de la revista homónima creada en 1928. Entre el yo y la alteridad, estos escritores construyen de modos muy distintos estos retratos. Cercana a este enfoque, Gilda Waldman (Universidad Nacional Autónoma de México) también estudia las diversas versiones que puede llegar a tener una vida en "Las vida(s) de Ernesto, El "Che" Guevara. Cuatro miradas biográficas y una novela”. Allí aborda cuatro miradas sobre la figura del famoso revolucionario desde la perspectiva de la escritura biográfica como un género fundamentalmente interpretativo, cuya reconstrucción del pasado es siempre parcial e incompleta. 
En el artículo de Julia Musitano (Universidad Nacional de Rosario / Conicet), "Fernando Vallejo biógrafo. La vida de los otros y la potencia de la autofiguración", se retoma la problemática de la relación entre biógrafo y biografiado. A partir de dos versiones de El mensajero, biografías que publicó el escritor Fernando Vallejo en 1984 y 1991, respectivamente, sobre Porfirio Barba Jacob, Musitano se detiene, por un lado, en una escritura biográfica que tensiona otras escrituras de vidas canónicas al romper, en el caso de la vida de Barba Jacob, con el relato cronológico y articulado. Por otro lado, su artículo se enfoca en dar cuenta de la escritura de vida como un proceso que en el caso de Vallejo también construye una autofiguración en la que median poéticas y afectos.

Finalmente, Lorena Amaro (Pontificia Universidad Católica de Chile) y Dunia Gras (Universidad de Barcelona), abordan, en sendos artículos, las posibilidades contemporáneas y ficcionales de la biografía. En “De la 'vida de artista' a la 'fábula biográfica': autores quiméricos en las obras de Bolaño, Bisama, Guebel y Pron", Amaro establece una relación entre el origen de las vidas de artistas, la preocupación decimonónica por las vidas infames y los artistas malditos, y las “fábulas biográficas" o biografías sobre autores inexistentes, creadas por cuatro autores latinoamericanos: los chilenos Roberto Bolaño y Álvaro Bisama, y los argentinos Daniel Guebel y Patricio Pron. Por su parte, Gras, en el artículo "Mario Bellatin y Shiki Nagaoka: la postfotografía como estrategia bioficcional del fake", analiza la obra del artista peruano-mexicano Mario Bellatin a la luz de sus relaciones con la imagen y la reapropiación y reciclaje de materiales fotográficos, particularmente en la biografía imaginaria Shiki Nagaoka: una nariz de ficción (2001), en que su autor explora, con retórica biográfica y como lo hacen también los autores analizados por Amaro, los límites entre realidad, ficción e impostura.

Lorena Amaro Claudia Darrigrandi 